\title{
Research on Cloud Service Platform and Model for Product Design
}

\section{Licheng Zong}

Northwest University, School of Arts, china 710069

175244567@qq.com

\author{
Keywords: Industry Design; Cloud Service; Service Mode; Design Service
}

\begin{abstract}
The rapid development of the Internet bring us into the era of large data, cloud computing as the core technology of information, the combination of cloud service and industrial design has opened up new ideas for collaborative design. Based on the study of the basic structure and technology of industrial design cloud service platform, this paper analyzes the architecture and characteristics of the existing Internet-based creative design platform, and puts forward the basic characteristics and innovative models of industrial design cloud service platform. Finally, build the industrial design cloud service platform model.
\end{abstract}

\section{Introduction}

Industrial design has played a great role in the promotion of human industrial civilization ${ }^{[1]}$, as the creative industry of industrial design, in the manufacturing industry in the process of upgrading, play a leading role in the manufacturing sector to guide the direction of development ${ }^{[2]}$. Industrial design is a creative-intensive industries, the various types of resources demanding, dependent on the degree of industrial design-related enterprises in order to keep up with changes in the market, so that the design of the product has a better sustainable development potential, in the collection of user demand information, both the quality and quantity have a relatively high demand, moreover, the consumer market is complex and volatile, and difficult to accurately predict, producers in the development of a new product often face relatively large business risk. At the same time, the design industry has its particularity, different from the traditional sense of the creative activities, product design behavior more dependent on a large number of effective user needs data, which means that the need to integrate a wide range of resources for the design service.

The emergence of digital design led to a new round of industrial revolution, the original mode of production is rapidly changing, mass production becomes no longer important, the core of the competition to how to meet consumer diversification, personalized demand. in such a big environment, the user is more tend to personalized, differentiated products, but also further enhance the user needs in product design in the important position.

In the new situation, industrial design not only from the function, form, emotional and other aspects of professional design activities ${ }^{[3]}$, the main design is not just a professional designer, design and daily life is closely related to people through the wisdom of life, Daily experience can be amateur design. In essence, the design is the comprehensive use of experience, so that everyone can become a designer, as long as there is a mature platform, we can like their own design. So we can see that the design of the form, place, appearance, quality, and even the feasibility is not important, the only important thing is how it is associated with people ${ }^{[4]}$.

In the background of large data, the original isolated individuals through the virtual space of internet to form a variety of communities, from the many ideas, information and wisdom in such a virtual space to share, collision, and continuous integration. Under the continuous impact of new technology, computer-aided design (CAD) digitalization, the use of design methods, the sharing of professional knowledge, the rise of 3D printing technology, these new technologies are the driving force for industrial design changes. 


\section{Industrial Design Cloud Services Overview}

Cloud services technology involves many disciplines, including statistics, data mining, machine learning, neural networks, social network analysis, signal processing, pattern recognition, optimization methods and visualization methods, these disciplines of specific technologies overlap each other, as shown in Fig. 1

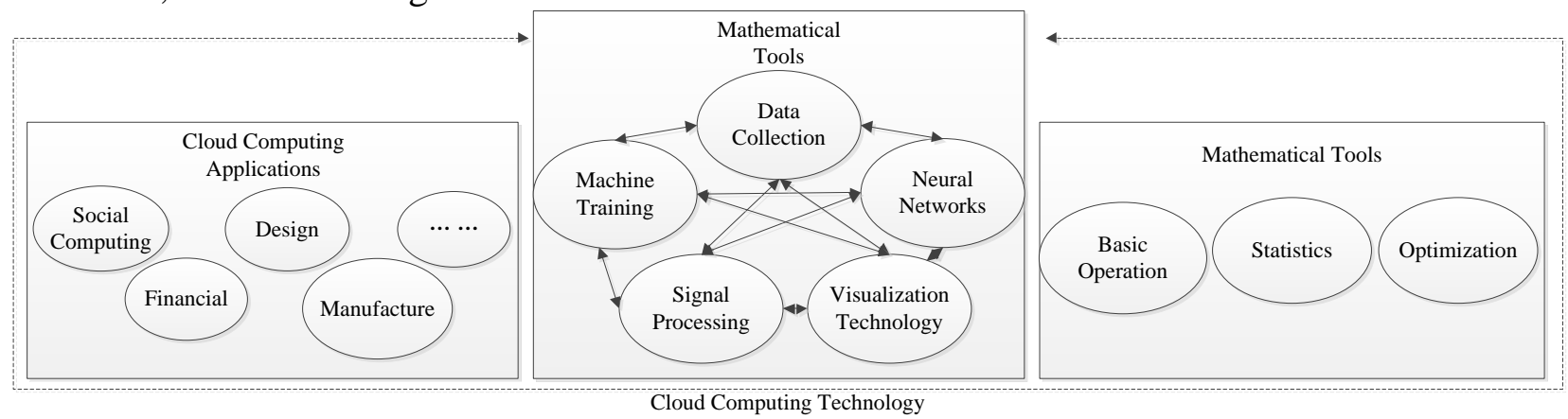

Figure 1. Finite Cloud computing technology

Cloud computing provides a challenge for data transfer and sharing, because the data and analysis of the cloud can be shared with others, but there are still some shortcomings, one is in the cloud environment to upload and download large amounts of data required time and cost is difficult to estimate; In addition, the distribution of computing and the underlying hardware becomes difficult to control; There is a public visit to the server data will face privacy issues, large data processing will promote the development of cloud computing to a higher level.

\section{Industrial Design Cloud Services Overview}

Industrial design as a new era of national innovation capacity of the embodiment, it represents the country's soft power, and has radiation around and actively promote the role of other industries, can effectively promote the optimization and upgrading of industrial structure. Therefore, the construction of a scale, a level of creative design service platform is necessary. Through the use of various types of information processing technology, a wide range of mass acquisition of creative resources, transmission of effective resources and the realization of a high degree of sharing of resources, so that the design of creative industry chain in all aspects of interconnection, this creative design service will be able to provide information for the industrial design creative industry, access, transmission, storage, retrieval and use of services.

Industrial design cloud services can be seen as networked collaborative design ${ }^{[5]}$, virtual manufacturing, agile manufacturing and other advanced models in the cloud computing environment integration and development, it inherited a variety of advanced design, manufacturing, marketing model advantages, combined with the characteristics of cloud computing to make up for the existing shortcomings and deficiencies, connect a variety of technical personnel to together in the world, which will be massive, decentralized, spontaneous innovation resources together to build an innovative service model, such a service model can fully reflect the wisdom of the group, establish an efficient innovation management mechanism, through innovation to achieve the sustainable development of enterprises, thus becoming the industry leader in the market.

Industrial design cloud services should be based on the majority of users, to all types of design as the main target, provide a design exchange, resource sharing, collaborative service platform, for the creative design of the industrial chain of upstream and downstream enterprises to provide business cooperation, resource sharing and other information. Services include the relevant government departments, all kinds of design enterprises, universities and research institutions, manufacturing enterprises, and other related industries. The use of information, mobile internet and other modern information technology as a means, the purpose of building such an information service platform is to efficiently collect the needs of massive users and promote the links between the parties, ease the flow of information and other issues, to promote the product's creative results quickly into products. 


\section{Analysis of Existing Relevant Creative Platform}

With the promotion of design service concept, some creative service platform is also rising, Table 1 on several major platforms to be analyzed:

Table 1 Comparison of Creative Service Platforms

\begin{tabular}{|c|c|c|c|c|}
\hline Project & Seek Dream & Seek Wish & zhubajie & 36 Krypton \\
\hline Modol & Crowdfunding & Crowdfunding & Witkey & Crowdfunding \\
\hline Specific Way & Project financing & Pre-order & Rewards & Equity financing \\
\hline Target Groups & Film investor & Star fans & $\begin{array}{c}\text { Design } \\
\text { enthusiasts }\end{array}$ & Financier \\
\hline Service Object & Filmmakers & Star & design needs & Entrepreneur \\
\hline Market & Film industry & Stars and fans & $\begin{array}{l}\text { Designers } \\
\text { demand and } \\
\text { providers }\end{array}$ & $\begin{array}{l}\text { Entrepreneurs } \\
\text { and investors }\end{array}$ \\
\hline Aging & Not fixed & Not fixed & $\begin{array}{c}\text { Depending on the } \\
\text { project }\end{array}$ & Fast \\
\hline Amount of Data & Smaller & Smaller & Larger & Larger \\
\hline
\end{tabular}

Although the creative platform above is also through the network resources to sharing and promote the development of an industry, but this article mentioned the cloud service platform is a new model, any person can become a creative initiator, in the cloud service, platform integration of all users of the creative can also use the cloud storage of manufacturing resources to become a reality, and continue to sell on the platform.

\section{Characteristics of Industrial Design Cloud Service Platform}

Based on the characteristics of cloud computing, many experts have done a lot of research on the characteristics of cloud innovation models, refer to these points of view and combine the characteristics of industrial product design, the characteristics of the cloud innovation platform for innovative design of industrial products, propose the characteristics of cloud innovation platform for industrial product innovation design ${ }^{[6]}$, cloud innovation is an active model active in the stage of innovation and diffusion, beyond the collaborative development of the group collaboration, is the network of service innovation model ${ }^{[7]}$, this paper presents the characteristics of cloud service platform for industrial design, include the following points:

The User's Breadth. The traditional product design is usually carried out by a professional designer, industrial design cloud service model to break the traditional design of innovative models, participate in the main product design innovation is no longer a single professional designers, but also more other non-professional staff together, as a broad audience for the innovative design model, in this mode, carry out a new design to mobilize all the relevant people who may be associated with the common participation in industrial product design, easy to promote cross-integration of different disciplines of knowledge, and to achieve significant innovation and breakthrough.

Design Timeliness. Industrial design cloud service platform, users can access from any network where they are covered, using a variety of client devices, designers no longer need a fixed time and place to start the program discussion and exchange ${ }^{[8]}$, whether it is a designer or a user, just use the internet to log on the cloud service platform anywhere, you can participate in design process. When people have a creative idea, you can through the cloud service platform in a timely connect with other people to communicate, share, discuss, you can arbitrarily extend and diverge your creativity, creating inspiration and designing new products.

Design Synergies. In the cloud service platform, design tasks be released by the management of the platform to the public, to promote the user on the platform to discuss the design, and submit the corresponding design to the platform, design solutions in the cloud service platform to display and accept the views of the majority of users, after several iterations, and ultimately get an optimal solution that is closest to the user's needs and satisfies the design task, therefore, based on industrial 
design cloud service platform, In fact, it is a set of industrial products around the design of a large number of design enthusiasts and users to participate in the collaborative design process.

The Reusability of Information. The design based on knowledge is a characteristic of modern design, the reusable design method is a knowledge-based design method that responds quickly to market demand. The process of classifying design knowledge based on reusability and improving the reusability of design knowledge is a meaningful research work ${ }^{[9]}$.

\section{Industrial Design Cloud Service Innovation Model}

The design pattern on the industrial design cloud service platform is a typical bottom-up public participation design pattern, it relies on the online community, hobbies designers can always use their computers to send their own design ideas to the cloud service community, through the judgment between each other, recommended to design their own personalized and differentiated product, this is a new design pattern. The traditional design pattern is a top-down process, through the repeated "research - design - test - feedback" makes the output of the product becomes the end of the design chain, that design is a business-centric, designer-led process, in the whole life cycle of the product process, businesses and designers have professional knowledge and experience, but in the design, user needs vision is still extremely limited, and in this limited field of view to measure the user's response is undoubtedly somewhat limited.

The model of cloud product design which user participate in the traditional design patterns, business, professional designers and ordinary users to design together. So that everyone involved in the design have feature of the user-centric, stimulate people's pursuit of real needs and the need for personalized experience. Enterprises or designers provide such a professional design to participate in the platform for the public, in the common creative design process with the user to dig, explore, express and find the real value of the needs and creativity, in order to achieve the design of the popular. In this design mode, the role and experience of traditional professional designers need to undergo profound changes, designers need to change the past top-down design thinking, digging the user's real needs, focus on the common parts of the design requirements, in the form of public participation, design a product family or design template with relevant characteristics, and then provide to the public participants, and then they work together to complete the product with different parts, the most important thing is to actively interact with the users of the networked community, on the one hand to obtain the needs of users, on the other hand can give them the necessary help, the mode show as Fig. 2. 


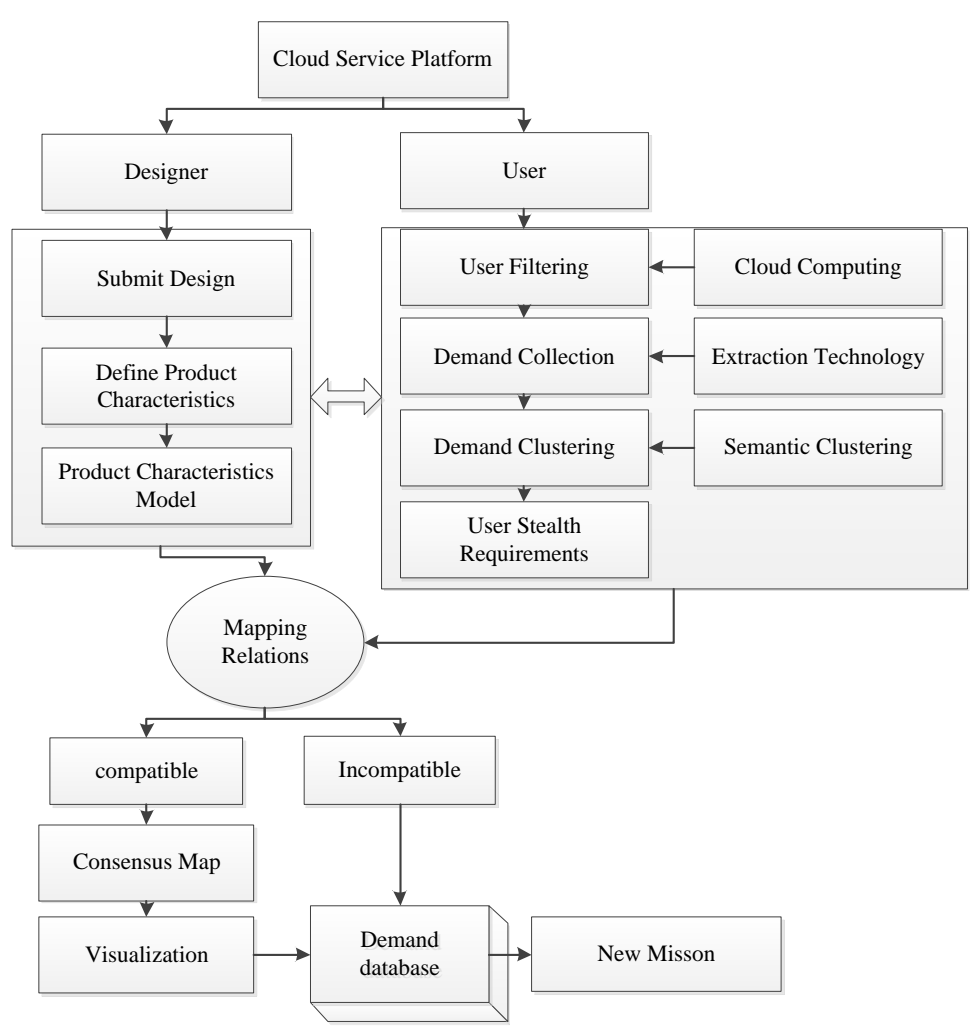

Figure 2. Finite the cloud service model of design

This model describes the industrial design cloud service platform is the designer, processor, producer, seller, user information integrated in a network platform, to achieve multi-collaborative design, highly shared resources, to provide users services at any time, and is conducive to the information update at any time to update the platform. This platform will provide enterprises from the creative needs, design, manufacturing to product marketing industry chain of the entire service process.

\section{Summary}

On the basis of introducing the change and development trend of industrial design under the new situation, through the introduction of cloud services, the basic concepts and applications, combine it with industrial design, and describe the industrial design cloud service, and discusses the significance of networked collaborative design to industrial design. Through some of the existing relevant creative platform for analysis and comparison, summed up the advantages and characteristics of industrial design cloud service platform, put forward the characteristics and operation mode of industrial design cloud service platform, build the industrial design cloud service platform in the context of large data innovation service model.

\section{Reference}

[1] LIU Guanzhong. Urgent need to re-understand the "Source" and "Yuan" of "Industrial Design" reflections on "Industry Chain" [J].ART, 2009

[2] STERN BERG R J, FORSYTHE G B, HED LUN J, et al .Practical intelligence in everyday life [ M ] . Cambridge, U K : Cambridge University Press, 2000.

[3] DU Shuxin. The key technology research of network collaborative system of industrial design[D]. Xi'an University of Electronic Science and Technology.2013

[4] HU Shuang. Research on the independent design caused by personal demand[D].Jiangnan University. 2010

[5] PETE R B, DEBBIE R. Modeling tacit knowledge via questionnaire data[J]. Lecture Notes in 
Computer Science, 2004,2961: 585-586.

[6] Maurer C., Overbeke C J., Smets G. The semantics of street furniture[C]. Proceedings of Object and Images Studies in Design and Advertising. Helsinki:University of Industrial arts. 1992: 86-93.

[7] LUO Shijian, PAN Yunhe, ZHU Shangshang. Patterns of tacit knowledge based on graphic thinking in product design[J]. Chinese Journal of Mechanical Engineering. 2007, 43(6): 93-98

8] Zhu Shangshang, Luo Shijian, Zhao Jianghong. A preliminary study on form image scale of numerical controlled machine tool based on human factors[J]. Journal of Computer aided Design\& Computer Graphics. 2000, 12(11): 873-875.

[9] LUO Shijian. The Status and Development Research of User 's Tacit Knowledge in Product Design[J]. Computer Integrated Manufacturing System, 2010 